\title{
ATELIER VIRTUAL INTERNACIONAL DE PROJETO DE ARQUITETURA - IVADS 2021
}

TALLER VIRTUAL INTERNACIONAL DE PROYECTO DE ARQUITECTURA - IVADS 2021

INTERNATIONAL VIRTUAL ARCHITECTURAL DESIGN STUDIO - IVADS 2021

\author{
VELOSO, MAISA \\ Doutora, Professora Titular da UFRN, coordenadora geral do IVADS 2021, E-mail: maisaveloso@gmail.com
}

\section{OS ATELIERS VIRTUAIS DE PROJETO}

Os ateliers virtuais de projeto (os chamados Virtual Design Studios) começaram a se desenvolver nos anos 1990 graças ao desenvolvimento da rede internacional de computadores (internet). Foi quando surgiram as primeiras experiências, sendo o projeto acadêmico pioneiro o realizado por Jerzy Wojtowicz, da Universidade de British Columbia/Canadá, o primeiro a utilizar a expressão VDS, segundo Araújo (2007). Os ateliers virtuais tinham o propósito inicial de reunir professores e discentes de diferentes escolas e culturas para desenvolvimento de projetos colaborativos, em ambientes diversos (presenciais e remotos), utilizando a web como meio de interação e os recursos informacionais de auxílio ao projeto, funcionando como verdadeiros intercâmbios culturais à distância.

Em pesquisa por nós coordenada sobre novas formas de ensino/aprendizado do projeto (VELOSO, 2019), iniciada antes do surgimento da pandemia causada pelo novo coronavírus, identificamos diversos tipos de ateliers de projeto, sendo os virtuais uma prática ainda pouco difundida na maioria das escolas de arquitetura, em especial nas brasileiras. Até o momento, foram mapeadas 52 experiências de ateliês virtuais, sendo 45 iniciativas estrangeiras e apenas 7 brasileiras. Dentre outras referências, devem-se destacar os experimentos do professor William Mitchell, do MIT, na década de 1990, tendo inclusive participação ativa na execução do Ateliê Virtual "Lisbon Charrette" em parceria com as Universidades de Lisboa e do Porto (MITCHELL, 2004). No âmbito latino-americano, o destaque vai para o "Taller Virtual de Las Américas", que realizou edições periódicas até muito recentemente. No Brasil, experiências relevantes foram vivenciadas principalmente por professores e estudantes da FAU-USP, IAU-USP e UFRJ em eventos realizados em parceria com outras escolas nacionais e estrangeiras. Em 2020, a Unicamp e a UFSC participaram da oficina internacional "Quadra do Futuro" dentro de um evento promovido pela Universidade Tongji (Xangai, China).

Nesse universo analisado, constatou-se a predominância de experiências realizadas de maneira virtual mas quase sempre associadas a atividades presenciais. Os fins são sobretudo pedagógicos, envolvendo principalmente estudantes de graduação de ao menos dois países/escolas distintos. O tempo de duração varia de 6 dias a até 16 semanas, conforme o caso. Os projetos são majoritariamente de cunho urbanístico e habitacional, direcionados a áreas sensíveis e/ou comunidades carentes das regiões estudadas. O caráter multidisciplinar e colaborativo dos VDS é reconhecidamente uma de suas características marcantes (CELANI, 2021; VÁSQUEZ DE VELASCO et al., 2006).

Contudo, apesar das avaliações em geral muito positivas feitas pelos atores envolvidos, os potenciais e os limites didático-pedagógicos desse tipo de atelier necessitam ainda ser mais bem avaliados, sobretudo em termos de rebatimentos no aprendizado do projeto, ainda mais quando os VDS passam a ser totalmente virtuais, por força da necessidade de distanciamento social imposta pela pandemia que nos aflige desde o início de 2020. Aulas, eventos e outras atividades se tornam repentinamente $100 \%$ on line e muito mais dependentes dos recursos informacionais. E o projetar também. Na grande maioria das escolas, o ensino presencial em atelier se converte em remoto de maneira muito rápida e sem muito tempo para capacitação de professores, estudantes e funcionários. As consequências, benéficas e maléficas, desse processo já têm sido avaliadas em diversas publicações (MONTEIRO, 2021; MEDEIROS, VELOSO, 2021). Não se deve, entretanto, confundir o VDS com o ensino presencial de projeto que foi forçado a ser remoto por conta da 
pandemia, nem tampouco com o chamado EaD (Ensino à Distância), concebido para funcionar predominantemente nesse modo, muito antes e independentemente de situações de riscos sanitários.

Foi nesse contexto pandêmico que, por ocasião da realização do $10^{\circ}$ Seminário Projetar Lisboa 2021 , foi realizada, no âmbito da programação pós-evento, uma experiência de atelier internacional de projeto 100\% on line, articulando ensino, pesquisa e prática.

\section{IVADS 2021 - GRUPO PROJETAR-UFRN / CIAUD-ULISBOA}

O International Virtual Architectural Design Studio - IVADS Projetando on line 2021 - foi organizado pelo Grupo PROJETAR da UFRN (Natal, Brasil) em parceria com o CIAUD da Universidade Lisboa (Portugal) ${ }^{1}$. Além de professores e estudantes majoritariamente destas duas instituições, também colaboraram com a experiência, por meio de convite, docentes e discentes da Unicamp (Campinas), IFSP (São Paulo) e UFPB (João Pessoa). O atelier teve carga horária total de 30 horas distribuídas em nove dias de atividades síncronas e assíncronas, ocorridas entre os dias 23 de novembro e 01 de dezembro de 2021 principalmente em ambientes do GMeet.

\section{São objetivos da Oficina:}

- a interação / colaboração entre professores e alunos no âmbito internacional acerca do tema "projetar virtualmente" para situações de crise (tema do $10^{\circ}$ Seminário Projetar 2021), à luz das discussões realizadas no próprio Seminário - informações no endereço https://projetar2021.wixsite.com/lisboa/calend\%C3\%A1rio );

- o fomento à multiculturalidade e à criatividade em oficinas dinâmicas realizadas virtualmente;

- o experimento prático acerca de novas formas e ferramentas de ensino e aprendizado do projeto em contextos de pandemia e pós-pandemia.

O tema projetual foi relacionado à temática geral do $10^{\circ}$ Seminário Projetar - Projetar em Contexto de Crise - convocando os participantes do atelier a conceberem uma habitação mínima/módulo habitacional emergencial para situações de catástrofe por eles definidas. As propostas deveriam ser desenvolvidas por quatro equipes, cada uma composta por seis estudantes das diferentes escolas (total de 24 alunos participantes), sob a supervisão de 3 professores orientadores - um da UFRN, outro da ULisboa e um terceiro de uma das escolas convidadas (total de doze professores envolvidos). Os meios de representação e de comunicação eram de livre escolha dos grupos. Foi utilizada a estratégia motivacional do concurso de ideias, em que seriam atribuídas aos projetos as classificações de primeiro lugar e até três menções honrosas, como resultado da avaliação de um júri de três especialistas convidados.

No primeiro dia, houve a apresentação do programa de atividades, a apresentação dos participantes e foram compostas as equipes de trabalho. Houve também uma inspiradora aula-palestra da professora doutora Ana Marta Feliciano da FAULisboa, sobre o tema da cabana primitiva e suas relações com a ideia fundamental de abrigo e a própria origem da arquitetura. Após a palestra, o doutorando Caio Castriotto, do PPG Arquitetura, Tecnologia e Cidade da Unicamp, fez uma apresentação sobre abrigos emergenciais contemporâneos, com um exemplo de execução de um protótipo. Compostas as equipes e seus respectivos professores orientadores, iniciaram-se os trabalhos no interior de cada grupo em ambiente virtual próprio e com usos de ferramentas múltiplas. No dia seguinte à abertura, cada equipe apresentou em sessão coletiva o problema/contexto, tema e conceito central de seu projeto, assim como as primeiras referências de projetos correlatos buscadas na internet. Professores orientadores e convidados fizeram suas considerações sobre as propostas iniciais, após o que os grupos voltaram a se reunir para planejar o desenvolvimento das atividades durante a semana. Após intensos debates e encontros que ocorriam muitas vezes durante a madrugada por conta do fuso horário Lisboa-Brasília, as apresentações finais das propostas ocorreram no dia 01 de dezembro, ocasião em que também foi feita, por meio de discussão coletiva, uma avaliação geral dessa primeira experiência do IVADS, considerada muito positiva pelos participantes que fizeram uso da palavra. Informações mais detalhadas e reflexões críticas mais abrangentes sobre essa experiência serão objeto de publicações futuras. Há também um formulário on line, com questões mais específicas, que está sendo aplicado pela doutoranda do PPGAU/UFRN, Carolina Nóbrega, como parte de sua pesquisa de doutorado, desenvolvida sob nossa orientação. Os resultados do concurso de ideias foram divulgados na semana seguinte (no dia 08 de dezembro), com indicação do primeiro lugar e a concessão de menções às outras três propostas, por decisão unânime do júri, composto pelos professores doutores Rubenilson Teixeira (UFRN), Hugo Farias (ULisboa) e Arthur Lara (USP).

Na seção Práxis dessa edição, além dessa breve introdução/resumo da experiência, são apresentados pelos próprios autores os principais produtos do IVADS 2021:

- $\quad$ O texto da professora Ana Marta Feliciano, intitulado A CABANA PRIMITIVA: CONTRIBUTOS PARA UMA TEORIZAÇÃO DA ARQUITECTURA, com parte do conteúdo da aula-palestra por ela ministrada; 
- O projeto classificado em primeiro lugar - RECONQUISTA DA IDENTIDADE: ABRIGOS EMERGENCIAIS PARA REFUGIADOS VENEZUELANOS - desenvolvido por Aléssio Dionisi et al.;

Apresentam-se, em seguida, as três menções honrosas:

- PARA TY: ABRIgo EMERgENCIAL PARA SituAÇÕES DE ENCHENTES E ALAGAMENTOS, por Haziel Lobo et al.;

- locus dA ESPERANÇA: PROJETO DE UM ABRIgO REgENERATIVO E ADAPTATIVO, de autoria de Lessandro Rosa et al:;

- $\quad$ ENTRE: PROPOSTA DE ABRIGO TEMPORÁRIO ADAPTÁVEL, desenvolvida por Camila Resende et al.

Figura 1: Sessão de abertura do IVADS 2021

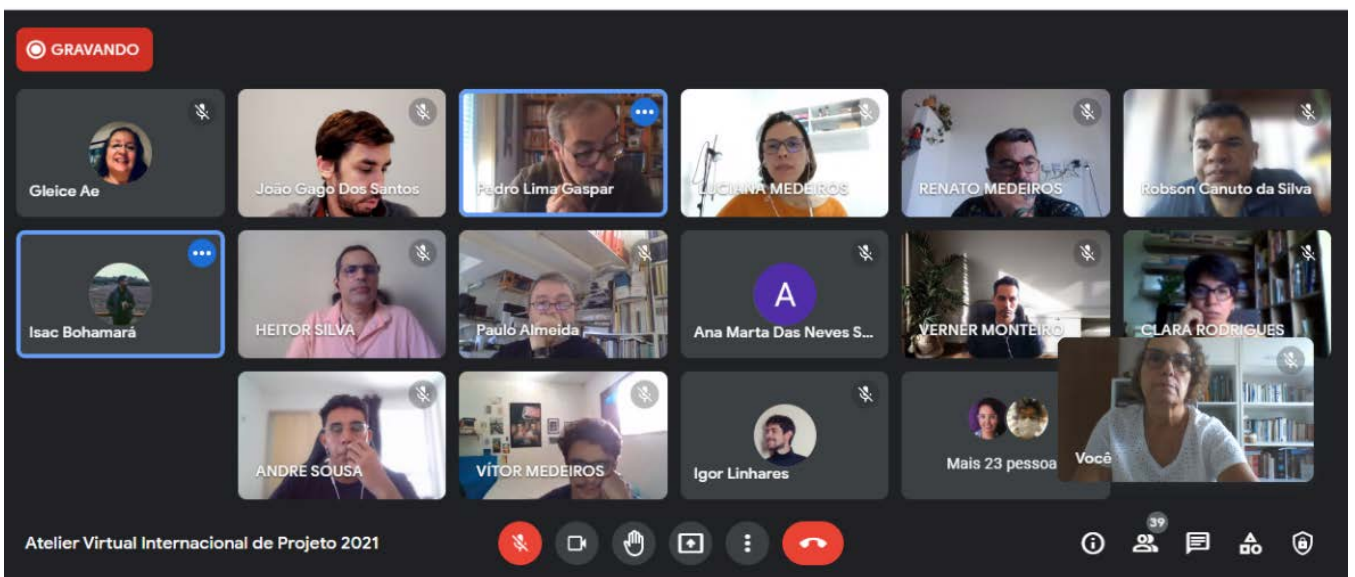

Fonte: Veloso, Maísa. 2021.

Figura 2: Sessão de encerramento / resultados finais do IVADS 2021

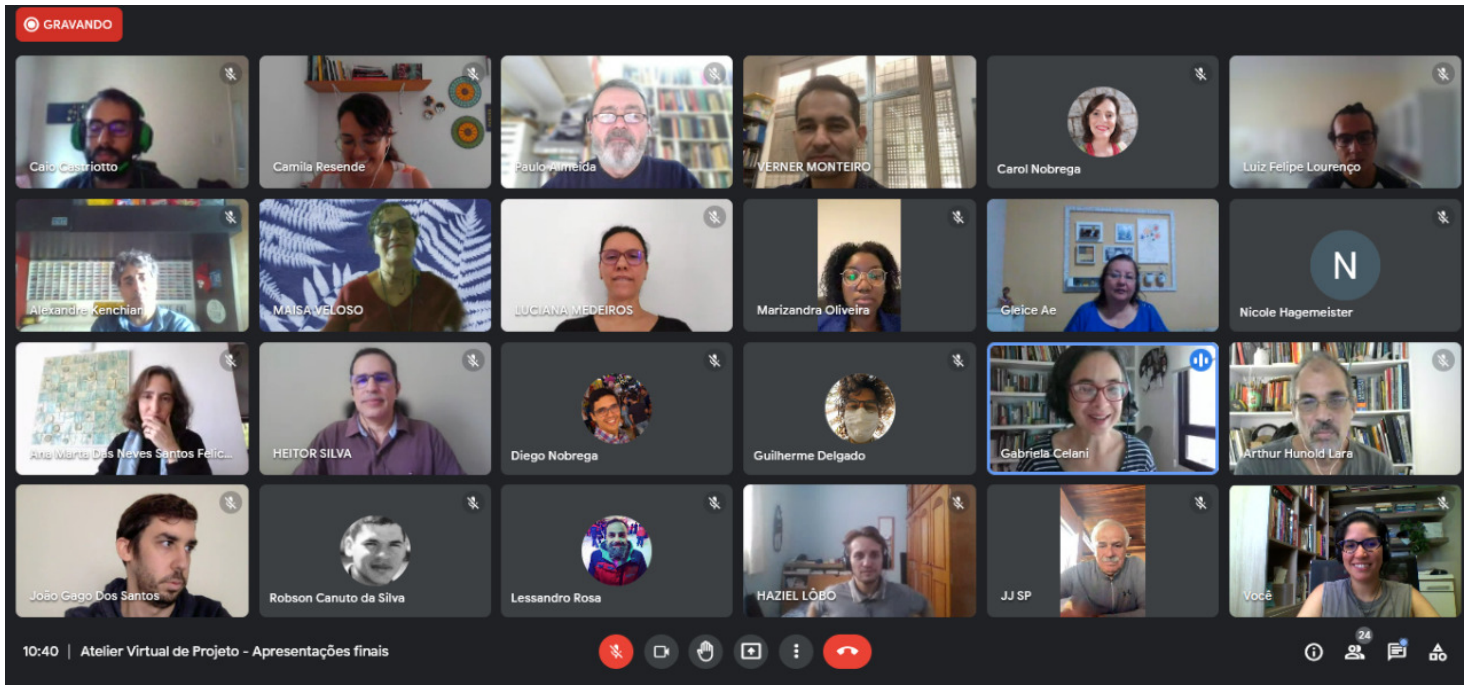

Fonte: Rodrigues, Clara. 2021.

\section{REFERÊNCIAS}

ARAÚJO, T. Projetos Colaborativos. Experiências interculturais na formação do arquiteto. Rio de Janeiro: Proarq/UFRJ. Tese de Doutorado, 2007.

CELANI, G.. Colaboração remota no projeto de arquitetura e urbanismo em um contexto de isolamento social. Revista Projetar - Projeto e Percepção do Ambiente, v. 6, n. 1, p.163-167, 25 jan. 2021.

MITCHELL, W. Challenges and Opportunities for Remote Collaborative Design, In: Massachusetts Institute of Technology, 2004.

MEDEIROS, R.; VELOSO, M. Potencialidades e limites do ensino remoto de projeto de arquitetura: a experiência de uma oficina virtual em contexto de pandemia. $10^{\circ}$ Seminário Internacional Projetar Lisboa 2021. In: Livro de Atas; 
ARQUITETURA, CIDADE E PAISAGEM: PROJETAR EM CONTEXTO DE CRISE - Novos Desafios para o Ensino, a Pesquisa e a Prática da Arquitetura. Lisboa, CIAUD/FAULisboa, 2021. ISBN: 978-989-53462-0-2.

MONTEIRO, A. G. Ensino de Arquitetura e Urbanismo à distância, remoto, híbrido: para onde queremos ir? Revista Projetar - Projeto e Percepção do Ambiente, v. 6, n. 1, p. 157-162, 25 jan. 2021.

VÁSQUEZ DE VELASCO, G. et al. Taller Virtual de Las Américas: Análisis, Síntesis y Propuesta de Desarrollo en Ambientes Multiusuarios Interactivos. In: Congresso Íbero Americano de Gráfica Digital, SIGraDi: Anais, Santiago, 2006.

VELOSO, M. Novas Pedagogias do Projeto de Arquitetura face aos desafios do século XXI. Brasília/Natal, CNPq, Processo n 308931/2018-1, 2019.

\section{NOTAS}

${ }^{1}$ PROJETAR - Grupo de Pesquisa em Projeto de Arquitetura e Percepção do Ambiente, da Universidade Federal do Rio Grande do Norte (UFRN); CIAUD - Centro de Investigação em Arquitetura, Urbanismo e Design, da Faculdade de Arquitetura da Universidade de Lisboa (FAULisboa). 